Revista Eletrônica de Direito Processual - REDP.

Rio de Janeiro. Ano 10. Volume 17. Número 1. Janeiro a Junho de 2016

Periódico Semestral da Pós-Graduação Stricto Sensu em Direito Processual da UERJ

Patrono: José Carlos Barbosa Moreira. ISSN 1982-7636. pp. 150-163

http://www.e-publicacoes.uerj.br/index.php/redp/index

\title{
ENTRE COMMON LAW E EQUITY: PRINCÍPIOS CONFLITANTES NA JUDICIALIZAÇÃO DO INTERESSE PÚBLICO NOS ESTADOS UNIDOS ${ }^{1}$
}

\section{BETWEEN COMMON LAW AND EQUITY: CONFLICTING PRINCIPLES IN AMERICAN PUBLIC INTEREST LITIGATION}

\begin{abstract}
Márcio de Paula Filgueiras
Professor de Ciências Sociais e Humanas no Instituto Federal do Espírito Santo. Doutor em Antropologia pelo Programa de Pós-Graduação em Antropologia da Universidade Federal Fluminense. Pesquisador ligado ao INCT- InEAC. Esta pesquisa foi financiada parcialmente por Capes/Fulbright. mpfilgueiras@gmail.com
\end{abstract}

RESUMO: Ações judiciais coletivas conhecidas como citizen suits permitem identificar algumas das problemáticas obrigatórias constitutivas do campo jurídico dos EUA, sobretudo as relacionadas a aspectos processuais da proteção judicial do interesse público. Seja olhando as citizen suits do ponto de vista das formas de produção da verdade, ou das noções de interesse público que as subjazem, é possível identificar uma tensão recorrente entre a dimensão política do processo e o formalismo processual. São como dois pólos, um informado por uma tradição mais próxima da sensibilidade jurídica de equity e outra mais próxima de uma sensibilidade jurídica de common law.

PALAVRAS-CHAVE: Ações Coletivas; EUA; Equity; Common Law

\begin{abstract}
Citizen suits allows us to identify some of the conditioning background of american legal field, particularly as regards procedural aspects of judicial protection of the public interest. Either looking at citizen suits from the point of view of the forms of production of truth, or the notions of public interest that underlies it is possible to identify a
\end{abstract}

\footnotetext{
${ }^{1}$ Artigo recebido em 15/11/2015 e aprovado em 26/04/2016.
} 
Revista Eletrônica de Direito Processual - REDP.

Rio de Janeiro. Ano 10. Volume 17. Número 1. Janeiro a Junho de 2016

Periódico Semestral da Pós-Graduação Stricto Sensu em Direito Processual da UERJ

Patrono: José Carlos Barbosa Moreira. ISSN 1982-7636. pp. 150-163 http://www.e-publicacoes.uerj.br/index.php/redp/index

recurring tension between the political dimension of the process and procedural formalities. They are like two poles, one informed by a equity tradition and the other closer to common law.

KEYWORDS: Colective Actions; US; Equity; Common Law

\section{Introdução}

Neste artigo vamos aplicar uma perspetiva familiar à Antropologia para analisar um instituto jurídico existente nos EUA, a saber, as citizen suits. Tomar uma perspectiva deste tipo significa que deixaremos o campo normativo do "dever ser", recorrente nos textos dos doutrinadores, para analisar, de maneira distanciada, os discursos jurídicos sobre tal instituto existentes no campo legal daquele país. Assim, nosso objetivo não é analisar o instituto em si ou avaliar sua eficácia, mas os discursos a respeito deste instituto e as questões que motivam as controvérsias entre os especialistas. Nosso pressuposto é o de que, em cada sociedade, os temas sobre os quais os especialistas divergem ou concordam são diferentes, já que informados pela cultura jurídica e política mais ampla na qual estão inseridos. Estas controvérsias, entendidas nestes termos, constituem o que Bourdieu (1989) chamou de "problemáticas obrigatórias". Abordaremos estes discursos a partir de duas problemáticas: a) a forma de produção da verdade expressa pelas citizen suits; b) a noção de interesse público expressa pelas citizen suits.

Apesar de também informado por um caso que acompanhamos através de observação direta na Califórnia ${ }^{2}$, este artigo empreende sobretudo uma análise dos discursos jurídicos presentes em textos do campo jurídico dos Estados Unidos. Para efeitos contrastivos, também faremos algumas referências à doutrina jurídica brasileira. Destaco que estes discursos jurídicos constituem parte da realidade social, lhe emprestando significados e referências semânticas (Kant de Lima, 2008). Assim, os textos dos especialistas norteamericanos cumprirão o papel de "textos deflagradores" (DaMatta, 1973) a partir dos quais

2

Durante estágio supervisionado financiado pela Capes/Fulbright na Universidade de Stanford, entre 2010 e 2011, como parte do doutorado defendido no Programa de Antropologia da Universidade Federal Fluminense, em 2012. 
Revista Eletrônica de Direito Processual - REDP.

Rio de Janeiro. Ano 10. Volume 17. Número 1. Janeiro a Junho de 2016

Periódico Semestral da Pós-Graduação Stricto Sensu em Direito Processual da UERJ

Patrono: José Carlos Barbosa Moreira. ISSN 1982-7636. pp. 150-163 http://www.e-publicacoes.uerj.br/index.php/redp/index

as categorias consideradas criticas pelos especialistas dos respectivos campos serão identificadas e compreendidas através de um exercício de comparação relativizadora, que busca destacar as especificidades de cada modelo.

A seguir veremos que, seja olhando as citizen suits do ponto de vista das formas de produção da verdade, ou das noções de interesse público que as subjazem, é possível identificar uma tensão recorrente entre, de um lado, a dimensão política do processo e sua capacidade de incorporar demandas voltadas para a regulação das relações sociais e econômicas complexas características da contemporaneidade e, de outro, o formalismo processual cercado de exigências técnicas que objetivam produzir previsibilidade jurídica. São como dois pólos, um informado por uma tradição mais próxima da sensibilidade jurídica de equity e outra mais próxima de uma sensibilidade jurídica de common law. As relações entre estes princípios conflitantes constituem aspectos fundamentais do sistema legal norteamericano.

\section{As citizen suits norte americanas}

A primeira coisa a destacar é que as citizen suits são ações legais permitidas aos cidadãos para a proteção do interesse público e estão baseadas em estatutos aprovados pelo legislativo. Estatutos são criados pelos legisladores, estaduais ou federais, para regular aspectos específicos da vida social e fazem parte de um processo de regulamentação da vida pública dos EUA que se intensificou sobretudo a partir das políticas do New Deal que tiveram como objetivo restabelecer a economia norte-americana depois da queda da bolsa de Nova York em 1929, a partir de intervenções federais sobre a economia e outros setores da vida social. Trata-se do campo do direito público ou administrativo americano.

Na década de 1970, os estatutos ambientais criaram novas agências reguladoras que seriam a resposta legislativa para superar os limites das cortes adversariais de common law, na administração de conflitos coletivos e tecnicamente complexos como os ambientais (Morag-Levine, 2003). Assim, ao invés de serem administrados através do direito de vizinhança tradicional nas cortes civis adversariais, surgiu a oportunidade de iniciar ações coletivas, chamadas citizen suits, que obedecem a um outro formato processual e que tem como referência um estatuto e não só os precedentes judiciais, como no direito civil de common law. 
Revista Eletrônica de Direito Processual - REDP.

Rio de Janeiro. Ano 10. Volume 17. Número 1. Janeiro a Junho de 2016

Periódico Semestral da Pós-Graduação Stricto Sensu em Direito Processual da UERJ

Patrono: José Carlos Barbosa Moreira. ISSN 1982-7636. pp. 150-163 http://www.e-publicacoes.uerj.br/index.php/redp/index

A adversariedade, atribuída ao sistema legal de common law dos EUA, designa um processo de produção da verdade conduzido pelas partes, e não pela Corte, além de marcadamente oral, ao invés de escrito, e público, ao invés de sigiloso, diferindo assim das práticas inquisitoriais, que geralmente são atribuídas aos países de Civil Law, como os da Europa Continental. No entanto, como veremos abaixo, práticas de origem inquisitorial também possuem uma trajetória na tradição anglo-americana, nas cortes de equity.

Diferente do que ocorre nos litígios civis comuns, marcadamente adversariais, as citizen suits retomam em grande medida a tradição processual inquisitorial de equity, o que se expressa, por exemplo, no papel mais ativo do juiz, na ausência de um júri e no tipo de remédios judiciais buscados, que não são compensações financeiras mas a interferência em políticas públicas através de obrigações de fazer ou não fazer (conhecidas como injunctions).

Como aponta Amalia Kessler (2004), junto da tradição adversarial dominante, o direito anglo-saxão possui uma tradição inquisitorial, ou "quasi inquisitorial" como prefere a autora, mas a respeito da qual os especialistas norte-americanos não seriam completamente autoconscientes, em função da associação tradicional entre Cortes inquisitoriais e a tirania real ou papal. As práticas adversárias, por outro lado, estariam relacionadas às conquistas inscritas no Bill of Rights, desfrutando da sacralidade dos textos fundacionais dos Estados Unidos, como observado também por Vincent Crapanzano (2000).

De acordo com Kessler, pouco se sabe sobre o desenvolvimento original das jurisdições de equity, mas está claro que tinham raízes profundas na tradição romanocanônica. Na Inglaterra, por volta do final do século treze, muitos litigantes começaram a fazer petições diretas ao Rei em busca de justiça, ao invés de se dirigirem às Cortes adversariais de common law, talvez porque as demandas que levavam às Cortes não se encaixassem nas exigências processuais de common law, cada vez mais rígidas em termos técnicos.

No século quatorze, como estas petições se tornaram mais numerosas, o conselho do rei começou a delegá-las a conselheiros individuais e dessas delegações surgiram uma série de Cortes, incluindo aquelas do Chanceler, as Chancelarias (Kessler, 2004). Durante o período de formação da "equity", o chanceler - frequentemente um eclesiástico - estatuía "segundo sua consciência", examinando com equidade cada caso em função das circunstâncias particulares do caso em questão. De onde a expressão consagrada to balance the equities of the case (Garapon \& Papadopoulos, 2008). No princípio do século dezessete, 
Revista Eletrônica de Direito Processual - REDP.

Rio de Janeiro. Ano 10. Volume 17. Número 1. Janeiro a Junho de 2016

Periódico Semestral da Pós-Graduação Stricto Sensu em Direito Processual da UERJ

Patrono: José Carlos Barbosa Moreira. ISSN 1982-7636. pp. 150-163

http://www.e-publicacoes.uerj.br/index.php/redp/index

quando as primeiras colônias inglesas foram criadas na América do Norte, o sistema de equity já estava bem estabelecido na Inglaterra. Embora as Cortes de equity tenham demorado relativamente a se desenvolverem nas novas colônias, cerca de 50 Cortes de chancelaria estavam estabelecidas em cada uma das treze colônias em 1776. (Kessler, 2004).

Esta discussão é muito mais longa e possui muito mais nuances do que apresentado aqui, mas para os objetivos deste artigo acreditamos que os termos fundamentais da controvérsia estão reunidos de maneira suficiente. Argumentamos que, apesar de uma auto imagem adversarial, os modelos processuais prevalecentes nos EUA expressam uma luta entre tradições jurídicas organizadas segundo princípios diferentes e algumas vezes conflitantes. $^{3}$

A seguir, mostrarei como nos estatutos ambientais podemos observar essas duas tradiçoes que habitam o campo jurídico norte americano, a de common law - adversarial- e a de equity - inquisitorial. Assim, irei propôr que alguns dos dilemas em relação às formas de produção da verdade e aos limites da definição do que seja interesse público no direito administrativo daquele país, resultam de como os estatutos ambientais desenvolveram-se a partir de certos princípios que expressam elementos tanto da tradiçao de equity quanto da tradiçao de common law. Isto permitirá identificar alguns dos termos principais da problemática processual da proteção do meio ambiente e do interesse público nos Estados Unidos, tendo como pano de fundo aspectos de suas tradições jurídicas e políticas mais amplas.

3.Aspectos não adversarias do processo de produção da verdade jurídica nas citizen suits

Como aponta Abram Cheyes (1976), o modelo de common law carregaria consigo um conjunto de convicções fortes sobre o papel do juiz, que deveria decidir apenas a respeito daquelas questões identificadas pelas partes. Atualmente, no entanto, nos casos envolvendo direito público e que afetam políticas públicas e uma gama mais ampla de interessados que o modelo adversarial tradicional, a função do juiz não é limitada à análise e afirmação das

3

Sugiro que não há relação necessária entre modelos processuais e sistemas jurídicos mais ou menos democráticos ou tirânicos, apesar de que diferentes grupos em diferentes contextos queiram produzir esta associação. 
Revista Eletrônica de Direito Processual - REDP.

Rio de Janeiro. Ano 10. Volume 17. Número 1. Janeiro a Junho de 2016

Periódico Semestral da Pós-Graduação Stricto Sensu em Direito Processual da UERJ

Patrono: José Carlos Barbosa Moreira. ISSN 1982-7636. pp. 150-163

http://www.e-publicacoes.uerj.br/index.php/redp/index

regras legais: ele é ativo, com responsabilidade não apenas pela determinação dos fatos mas por organizar e moldar o processo.

De acordo com Cheyes, esta mudança expressa o crescimento de elementos de equity nas Cortes federais, já que historicamente o chancellor era o julgador dos fatos nas Cortes de equity. $\mathrm{O}$ autor, que se posiciona como entusiasta de institutos como as citizen suits, aponta que a lógica por trás deste papel acentuado do juiz talvez seja o fato de que "o assunto objeto da ação não é uma disputa entre partes privadas a respeito de direitos privados, mas uma queixa a respeito da operação de políticas públicas" (p. 1302, 1976).Todos estes fatores recolocam o papel do juiz no direito administrativo quando comparado a seu papel nas Cortes adversariais de common law:

O juiz é a figura dominante na organização e direção do caso e ele utiliza o apoio não só das partes e seus advogados, mas de uma série de outsiders como masters e especialistas. Ainda mais importante, o juiz tem tornado-se cada vez mais o criador e gerenciador de formas complexas de remédios judiciais que possuem efeitos em pessoas e grupos que não estão presentes na Corte, o que exige do juiz o contínuo envolvimento em sua administração e implementação (p,1302,1976).

Assim, nas citizen suits o tipo de processo difere significativamente do processo civil adversarial tradicional das Cortes de common law. Uma das diferenças é que não há um juri (jury trial). Nestes casos o juiz debruça-se sobre um relatório produzido pela agência reguladora, designada pelo legislativo para a implementação do estatuto e verifica se as decisões tomadas pela agência são justificáveis levando em consideração as informações apresentadas pelo relatório. Outra diferença é que nestas Cortes que decidem sobre questões suscitadas pelos estatutos ambientais não há a tradicional "guerra de especialistas" típicas dos casos julgados nas Cortes civis de common law, ou seja, não haverá outros especialistas para contestar os dados da agência. Os grupos que estiverem challenging, ou seja, desafiando legalmente as decisões da agência podem enviar seus relatórios à agência - não à Corte - e a agência deve incorporá-los ao seu relatório final a ser apresentado ao juiz. Assim, a forma como está organizado o processo expressa um grande acatamento à expertise das agências ${ }^{4}$.

4

A expressão Chevron deference, por exemplo, remete ao caso Chevron U.S.A. Inc. v. Natural Resources Defense Council, Inc., 467 U.S. 837 (1984) em que a Corte determinou que a Enviromental Protection Agency (EPA) compreende o Clean Air Act, estatuto que regula emissão de gases, melhor que a Corte e que, portanto, esta deve prestar acatamento à agência sempre que o Congresso tenha sido impreciso na 
Revista Eletrônica de Direito Processual - REDP.

Rio de Janeiro. Ano 10. Volume 17. Número 1. Janeiro a Junho de 2016

Periódico Semestral da Pós-Graduação Stricto Sensu em Direito Processual da UERJ

Patrono: José Carlos Barbosa Moreira. ISSN 1982-7636. pp. 150-163

http://www.e-publicacoes.uerj.br/index.php/redp/index

Como geralmente não há jury, nem examination e cross examinations seja de

testemunha ou experts, ou seja, não há o processo de produção pública e oral dos fatos, não há também o efeito do demeanor ou comportamento público das testemunhas presentes nas Cortes de common law que representa um elemento importante das formas de produzir verdade no ritual do jury trial americano (Kessler, 2004). Isto nos foi confirmado em pesquisa de campo nos EUA, enquanto acompanhávamos as discussões acerca da construção de um trem de alta velocidade entre Los Angeles e San Francisco. O advogado que representava um grupo de cidades e associações que queriam alterar o trajeto do trem, nos explicou que uma das consequências deste modelo de processo é que as decisões são mais passíveis de apelação, já que carecem do fact finding effect dos jury trials.

Fact finding, neste sentido, designa um processo de produção da verdade relacionado à tradição adversarial de common law, ou seja, controlado pelas partes. Ele está baseado na busca de informações, evidências sobre acontecimentos e condutas, que é conduzida não pelo juiz ou por um especialista designado pela Corte, como na tradição inquisitorial, mas depende em grande medida da capacidade e dos recursos dos advogados das partes em litígio. Estas evidências, quando consideradas fatos pelo veredito do jury, após processo públicos de examination e cross examination produzem, nos EUA, efeitos de verdade menos passíveis de apelação do que os casos julgados somente pelo juiz.

De acordo com Cheyes (1976), estas mudanças processuais expressas pelas citizen suits levantariam sérias preocupações sobre legitimidade. Assim, diferente do que podemos observar no Brasil, onde a inquisitorialidade é naturalizada pela doutrina ${ }^{5}$, Cheyes indica haver uma questão de legitimidade no campo jurídico norte-americano relativa às relações entre uma tradição adversarial que vê com maus olhos um juiz ativo, relacionado pejorativamente com inquisitorialidade e o papel cada vez maior que remédios vindos das cortes de equity, assim como elementos processuais de origem inquisitorial, desempenham

linguagem do estatuto e que a interpretação da agência não seja arbitrária ou caprichosa. Naquele caso, a $E P A$ havia estabelecido que indústrias poderiam implementar novas fontes emissoras de gases, mesmo que estes emitissem além dos limites estabelecidos pelo plano federal, se, dentro da mesma planta industrial a soma das emissões se mantivese estável. Apesar da agência ter sido desafiada por grupos em defesa do meio ambiente, a Corte decidiu que, como a linguagem do estatuto não era precisa a este respeito, iria acatar a posição da EPA. 5

Isso está claro em autores como Dinamarco (2005); Rodrigues (2003); Grinover (2005), para quem, em casos envolvendo interesse público, o juiz deve ser ativo na busca pela verdade real. Para estes autores, em casos envolvendo o interesse público, deixar que as partes conduzam a busca pelos fatos, ou seja, submeter o processo ao que chamam de "princípio dispositivo" é uma ameaça ao interesse público. 
Revista Eletrônica de Direito Processual - REDP.

Rio de Janeiro. Ano 10. Volume 17. Número 1. Janeiro a Junho de 2016

Periódico Semestral da Pós-Graduação Stricto Sensu em Direito Processual da UERJ

Patrono: José Carlos Barbosa Moreira. ISSN 1982-7636. pp. 150-163 http://www.e-publicacoes.uerj.br/index.php/redp/index

nos casos de conflitos ambientais ou outras complex litigations, ou seja, em outros casos legais complexos.

Como aponta Kessler (2004), os americanos têm dificuldade em reconhecer a origem não adversarial de diversos elementos de seus sistema jurídico, por causa da associação histórica entre as cortes de equity e a tirania monárquica. Assim, o fato de que estes elementos sejam cada vez mais considerados necessários atualmente mostra bem claramente como a cultura jurídica americana expressa uma luta interna por legitimidade entre modelos de produção da verdade e de acesso à justiça.

No entanto, como mostro a seguir, os estatutos ambientais norte-americanos incorporaram também, ainda que de maneira ambígua e paradoxal, elementos significativos das Cortes adversariais de common law. Como veremos, enquanto a influência de princípios de common law no direito administrativo é legitimada politicamente como instrumento de proteção contra os excessos das agências reguladoras, por outro lado, algumas exigências técnicas de common law, ao limitarem o alcance da noção de interesse público designada pela categoria public interest, podem dificultar a implementação de determinadas regulações ou impedir que grupos iniciem ações judiciais.

4. A influência da common law sobre os estatutos ambientais e a definição do alcance do interesse público

Vimos acima como nos EUA os litígios coletivos suscitam questões sobre os limites dos modelos adversariais e a necessidade de um novo papel, mais ativo, para o juiz administrar a complexidade destes casos. As citizen suits, de fato, retomam aspectos da tradição de equity, que se afasta do modelo adversarial tradicional. Mas, se por um lado, a tradição de equity redefiniu o papel do juiz, por outro, aspectos da tradição de common law continuam se reproduzindo, sobretudo nas exigências formais para iniciar uma citizen suits.

Estas exigências processuais constituem o que é conhecido como standing to sue tests. Um de seus aspectos é a exigência de que haja um dano concreto para que um cidadão inicie uma citizen suit, ou seja, ele e seu grupo devem possuir um interesse concreto no usufruto de uma área natural e não agir simplesmente para proteger a natureza "para toda a sociedade". 
Revista Eletrônica de Direito Processual - REDP.

Rio de Janeiro. Ano 10. Volume 17. Número 1. Janeiro a Junho de 2016

Periódico Semestral da Pós-Graduação Stricto Sensu em Direito Processual da UERJ

Patrono: José Carlos Barbosa Moreira. ISSN 1982-7636. pp. 150-163 http://www.e-publicacoes.uerj.br/index.php/redp/index

Assim, apesar de terem surgido com a promessa de proteger o meio ambiente de maneira ampla, para "todos os americanos", os estatutos ambientais acabaram sendo limitados por exigências processuais da tradição jurídica de common law, aplicadas pelas Cortes, o que implicou em um estreitamento do alcance do interesse público que os cidadãos pudessem reivindicar judicialmente. Este estreitamento do acesso à justiça pode ser visto na narrativa apresentada por Morag-Levine (2003). De acordo com ela seu interesse acadêmico pelo tema se entrecruza com a experiência pessoal que teve quando sua família mudou-se para Albany, Califórnia. Desde a chegada ao novo apartamento, sua família teria notado o cheiro de plástico queimado que irritava e causava ardência nos olhos e narizes e um gosto amargo na boca. Estes efeitos variavam com a intensidade e direção dos ventos. Sendo mãe de duas jovens garotas, decidiu junto de seu marido investigar as razões e origem daquela fumaça. Descobriram então que a agência regional responsável pelo assunto era a Bay Area Air Quality Management District (BAAQMD). Sua residência foi visitada então por um inspetor que lhes explicou que a fumaça provinha de uma metalúrgica e que aqueles gases incluiam substâncias tóxicas e nocivas à saúde. Foi lhe explicado também que para que a agência tomasse providências, era preciso que aquela fumaça constituísse uma public nuisance, ou seja, uma perturbação no usufruto do ar pela vizinhança.

Acontece que para que uma public nuisance fosse reconhecida, era preciso que cinco reclamações fossem verificadas pelo inspetor na vizinhança em um período de 24 horas. Ora, como os ventos mudavam de direção e intensidade desde o telefonema da agência até a chegada do inspetor, foram inúmeras as visitas frustradas do representante da agência até que os critérios para o estabelecimento de uma public nuisance fossem estabelecidos. Segundo a autora, a situação parecia algumas vezes surreal, com inspetores e vizinhos tentando sentir o cheiro de plástico queimado pelas redondezas. No entanto, ela diz que os inspetores lhe pareciam pessoas sérias que agiam de boa fé, mas cuja função era a de árbitros em um jogo cujas regras eram aplicadas com convicção, mas que pareciam carecer de lógica. Foi então ficando claro para Morag-Levine que a agência compreendia seu papel como o de um árbitro neutro agindo entre os interesses da vizinhança e da metalúrgica e não como um órgão regulador com uma missão regulatória como um fim em si mesma.

6. Como expresso por exemplo no discurso do ex- presidente americano Richard Nixon de que a partir da década de 1970 "todos os americanos" deveriam respirar ar puro. Ver: "Clean air, clean water, open spaces" (...) "ought to be the birthright for every American" (Public Papers of the President: Richard Nixon 8, 13(1970) apud Morag-Levine, 2003) 
Revista Eletrônica de Direito Processual - REDP.

Rio de Janeiro. Ano 10. Volume 17. Número 1. Janeiro a Junho de 2016

Periódico Semestral da Pós-Graduação Stricto Sensu em Direito Processual da UERJ

Patrono: José Carlos Barbosa Moreira. ISSN 1982-7636. pp. 150-163 http://www.e-publicacoes.uerj.br/index.php/redp/index

Este modelo de controle da poluição lhe pareceu difícil de compreender tendo em vista que o estatuto Clean Air Act (CAA, 1970) era visto geralmente como uma resposta estatutária aos fracassos identificados no sistema de justiça. No entanto, sua pesquisa acabou por mostrar que, ao invés de expressar aspectos residuais da tradição de common law, o CAA na verdade estava estruturado ao redor de uma sensibilidade jurídica de common law bem estabelecida. Esta está centrada sobretudo na demanda de proof of harm. Quando traduzida para o papel das agências reguladoras, esta demanda implica que a agência só pode regular emissões que estejam comprovadamente causando injuries, isto é, danos legalmente reconhecíveis. Caso contrário serão acusadas pelas indústrias de regular negócios privados além dos limites constitucionais.

Assim, a legitimidade para propor uma "citizen suit" ou, em outras palavras, "to have standing", depende de alguns quesitos que, por sua vez, ajudam também a compreender os termos do entendimento do que seja interesse público na cultura jurídica americana. Como aponta Alec Stone Sweet:

Pressupõe-se que as Cortes americanas devem negar standing às partes que fracassem em mostrar algum grau de interesse direto na revisão de algum ato público, apesar de que as doutrinas que dizem respeito ao standing tenham conquistado fama de serem pouco claras, além de instáveis (p.2270, 2003. Grifo nosso)

Dessa maneira, apesar de alguns estatutos usarem a expressão any citizen, ou seja, "qualquer cidadão", para se referir a quem pode iniciar uma citizen suit, as Cortes se preocupam em determinar o standing, observando se os queixosos são diferentes, de algum forma, do público em geral. A mera existência de violações legais não produz dano no seu sentido legal de permitir uma citizen suit. Para iniciar uma citizen suit os queixosos precisam demonstrar que as violações legais lhes causaram injuries, ou seja, danos específicos.

Como a Corte argumentou em Steel Co. v. Citizens for a Better Environment, 118 S.Ct. 1003 (1998), representar um undifferentiated public interest, ou seja, um interesse público indiferenciado, não fornece standing no direito administrativo americano:

Naquele caso, o requerente buscou penalidades civis através do (estatuto) EPCRA pelo fracasso do requerido em armazenar produtos químicos tóxicos e emitir relatórios. A

7

A doutrina do "standing" está baseada no terceiro artigo da constituição dos EUA que limita a jurisdição das Cortes federais aos "casos" e "controvérsias" (Kenneth C. Gold; Recent Cases Impact Citizen Suit Standing - Michigan Lawyers Weekly, Vol. 13, No. 47, September 27, 1999.) 
Revista Eletrônica de Direito Processual - REDP.

Rio de Janeiro. Ano 10. Volume 17. Número 1. Janeiro a Junho de 2016

Periódico Semestral da Pós-Graduação Stricto Sensu em Direito Processual da UERJ

Patrono: José Carlos Barbosa Moreira. ISSN 1982-7636. pp. 150-163 http://www.e-publicacoes.uerj.br/index.php/redp/index

opinião da Corte, escrita pelo Juiz Antoni Scalia, observou que, porque as penalidades seriam pagas ao tesouro federal norte-americano e não ao requerente, estas penalidades não serviriam para ressarcir o requerente por dano algum que este tivesse sofrido pelas violações do requerido. Ao invés disso, o requerente estava meramente buscando o cumprimento da lei, o que constitui um dano não ao requerente mas a um interesse público indiferenciado (grifo nosso) ${ }^{8}$

Assim, pode-se observar que os estatutos ambientais, se por um lado teriam sua origem relacionada a um desejo em determinar um interesse público amplo, a ser determinado pelas agências reguladoras, superando assim os limites das Cortes de common law, acabaram incorporando mecanismos desta mesma tradição legal, sobretudo exigências processuais que limitam o poder dos cidadãos de iniciarem ações. Resulta disso uma concepção hegemônica de interesse público bem mais limitada do que aquela com a qual estamos familiarizados no Brasil.

Em nosso país, entidades como o Ministério Público podem iniciar ações para proteção do meio ambiente sem necessariamente identificar grupos específicos que estejam sofrendo um dano concreto no usufruto de uma área natural. Trata-se de uma concepção "difusa" de interesse público que corresponde a bens "indivisíveis" e a sujeitos indeterminados, à sociedade "como um todo", enquanto nos EUA a categoria public interest tem sido interpretada segundo a lógica de common law, ou seja, de maneira mais atomista, pensando o public como representando grupos específicos que possuam interesses concretos.

O que sugerimos é que, seja olhando as citizen suits do ponto de vista das formas de produção da verdade, ou das noções de interesse público que as subjazem, é possível identificar uma tensão recorrente entre, de um lado, a dimensão política do processo e sua capacidade de incorporar demandas voltadas para a regulação das relações sociais e econômicas futuras mais amplas e, de outro, o formalismo processual cercado de exigências técnicas que objetivam produzir previsibilidade jurídica. São como dois pólos, um informado por uma tradição mais próxima da sensibilidade de equity e outra mais próxima de uma sensibilidade de common law. As relações entre estes princípios conflitantes constituem aspectos fundamentais do sistema legal norte-americano.

\footnotetext{
8 20/04/20115.

Disponível em: https://supreme.justia.com/cases/federal/us/523/83/case.html. Acesso em
} 
Revista Eletrônica de Direito Processual - REDP.

Rio de Janeiro. Ano 10. Volume 17. Número 1. Janeiro a Junho de 2016

Periódico Semestral da Pós-Graduação Stricto Sensu em Direito Processual da UERJ

Patrono: José Carlos Barbosa Moreira. ISSN 1982-7636. pp. 150-163 http://www.e-publicacoes.uerj.br/index.php/redp/index

\section{Considerações finais}

A constatação de que o sistema judicial norte-americano expressa a ação de princípios conflitantes, oriundos de diferentes tradições processuais, coloca questões sobre as relações entre sistemas legais e identidades nacionais. Isso porque, historicamente, estabeleceu-se no Ocidente uma rivalidade entre modelos processuais, que explora os contrastes entre as práticas judiciais predominantes na Europa Continental, que remontam à tradição inquisitorial, católica e romana e aquelas prevalecentes nos países anglofônicos, marcadamente adversariais.

No contexto da comparação entre as ideologias nacionais de França e Alemanha, Dumont (1994) destacou que o que caracteriza a ideologia nacional de uma sociedade é aquilo que salta aos olhos do observador, quando este a contrasta com a ideologia nacional de outra sociedade. Neste sentido, as identidades nacionais são relacionais, já que não podem ser definidas em si, mas sim na relação que estabelecem umas com as outras.

$\mathrm{O}$ mesmo acontece nas relações entre tradições legais e identidades nacionais. Se quando comparamos os sistemas legais dos Estados Unidos e da França é a herança católica que parece ser um dos diacríticos franceses principais, ao compararmos França com Brasil, é o segundo que parece mais englobado pela sensibilidade jurídica católica, enquanto saltam aos olhos os aspectos liberais das práticas judiciais francesas, quando contrastadas com nossa inquisitorialidade (Garapon \& Papadupoulos, 2008; Kant de Lima, 2008).

Assim, os elementos apresentados aqui devem servir para nos afastarmos das leituras essencialistas, substituindo-as pelo reconhecimento de que os modelos hegemônicos em cada sociedade expressam, na verdade, histórias e disputas políticas específicas e que só tomam sentido quando as situamos no contexto de cada sociedade nacional.

Acreditamos que o caso dos conflitos envolvendo interesse público nos EUA mostra claramente que ambas as tradições identificadas, a de equity e a de common law, possuem limites e potencialidades que tem sido exploradas politicamente ao longo da história daquele país. Este uso político do processo legal já fora denunciado por Laura Nader (2002), quando criticou o movimento por Resolução Alternativa de Conflitos que, ao incentivar acordos privados, tornaria a justiça mais célere, além de oferecer uma solução negociada e, portanto, mais "harmônica" para os conflitos. Segundo a autora, este movimento representaria na 
Revista Eletrônica de Direito Processual - REDP.

Rio de Janeiro. Ano 10. Volume 17. Número 1. Janeiro a Junho de 2016

Periódico Semestral da Pós-Graduação Stricto Sensu em Direito Processual da UERJ

Patrono: José Carlos Barbosa Moreira. ISSN 1982-7636. pp. 150-163

http://www.e-publicacoes.uerj.br/index.php/redp/index

verdade uma alternativa conservadora para lidar com os usos dos Cortes por grupos minoritários, como negros e mulheres, a partir das décadas de 1960-70. Estas negociações privadas, feitas fora da supervisão de um juiz, favoreceriam jogadores experientes, como o Estado e as grandes corporações.

Em sentido parecido, a leitura dos textos de especialistas legais norte-americanos, simpáticos às causas ambientais, mostra que, do ponto de vista deles, a reprodução de princípios de common law no direito administrativo, representa uma reação conservadora das Cortes contra a linguagem dos estatutos ambientais, que dizem que qualquer cidadão (any citizen) poderia iniciar uma ação deste tipo (Morag-Levine, 2003). Outros autores, por outro lado, saúdam este tipo de limitação processual, como forma de manter as Cortes protegidas de usos "ideológicos" e "políticos" de ações judiciais por parte de grupos militantes ${ }^{9}$. Neste sentido, as citizen suits parecem uma oportunidade interessante de observar como uma sociedade reproduz seu sistema de justiça em contextos políticos novos, como os suscitados pela judicialização do meio ambiente e de outros temas de interesse público.

\section{REFERÊNCIAS BIBLIOGRÁFICAS:}

BOURDIEU, Pierre. A economia das trocas simbólicas. Editora Perspectiva. São Paulo, 1987.

CHAYES, Abram. The Role of the Judge in Public Law Litigation, 89 HARV. L. REV. 1281, 1976.

DAMATTA, Roberto. Ensaio de Antropologia Estrutural, Ed. Vozes, Petrópolis, 1973.

DINAMARCO, Cândido Rangel. A instrumentalidade do processo. 12 edição. Malheiros Editores. 2005.

DUMONT, Louis. German Ideology: from France to Germany and back. The University of Chicago Press. 1994.

9

Ross Sandler, em entrevista concedida ao autor deste artigo. Ross Sandler é diretor fundador do "New York Law School's Center for New York City Law". É membro do corpo docente da New York Law School. É também um membro do New York Procurement Policy Board. Ver também seu artigo: Sandler, Ross \& Democracy by decree: what happens when courts run government. Yale University Press, 2004. 
Revista Eletrônica de Direito Processual - REDP.

Rio de Janeiro. Ano 10. Volume 17. Número 1. Janeiro a Junho de 2016

Periódico Semestral da Pós-Graduação Stricto Sensu em Direito Processual da UERJ

Patrono: José Carlos Barbosa Moreira. ISSN 1982-7636. pp. 150-163 http://www.e-publicacoes.uerj.br/index.php/redp/index

FILGUEIRAS, Márcio De Paula. Aspectos processuais dos direitos ambientais do Brasil e dos Estados Unidos da América: produção da verdade, acesso a direitos e interesse público em perspectiva comparada. Tese apresentada ao Programa de Pós-Graduação em Antropologia da Universidade Federal Fluminense. Niterói, 2012.

GARAPON, Antoine \& Papadopoulos, Ionnes. Julgar nos EUA e na França: cultura jurídica francesa e common law em perspectiva comparada. Lumen Juris. 2008.

GRINOVER, Ada Pellegrini. Rumo a um Código Brasileiro de Processos Coletivos. IN: A Ação Civil Pública após 20 anos: efetividade e desafios. Editora Revista dos Tribunais. 2005. KANT DE LIMA, Roberto. Ensaios de Antropologia e de Direito. Rio de Janeiro: Lumen Juris. 2008.

KESSLER, Amalia. Our inquisitorial tradition: equity procedure, due process and the search to the alternative to the adversarial. Research Paper No. 98 December 2004. Working Paper Series. Stanford. 2004.

NADER, Laura. The life of the Law: anthropological projects. University of California Press. 2002

MORAG-LEVINE, Nora . Chasing the wind: regulating air pollution in the common law state. Princeton.Princeton University Press, 2003.

OLIVEIRA, Roberto Cardoso de (org.). MAUSS. São Paulo: Ática, 1979.

RODRIGUES, Marcelo Abelha. Ação civil pública e meio ambiente. São Paulo: Forense Universitária, 2003.

SANDLER, Ross. Democracy by decree: what happens when courts run government. Yale University Press, 2004.

STEWARD, Richard. The Reformation of American Administrative Law. Harvard Law Review. Vol.88. No. 8. 1975.

SWEET, Alec Stone. Why Europe Rejected American Judicial Review and Why it May Not Matter. Faculty Scholarship Series. Yale Law School, 2003. 